\title{
Determination of flavor-potentiating compounds in different Italian tomato varieties
}

Giuseppina Tommonaro, ${ }^{a^{*}}$ Carlo F. Morelli, ${ }^{b}$ Marco Rabuffetti, ${ }^{c}$ Barbara Nicolaus, ${ }^{a}$ Rocco De Prisco, ${ }^{\text {a }}$ Carmine Iodice, ${ }^{\mathrm{a}}$ Giovanna Speranza,, $\mathrm{d}$

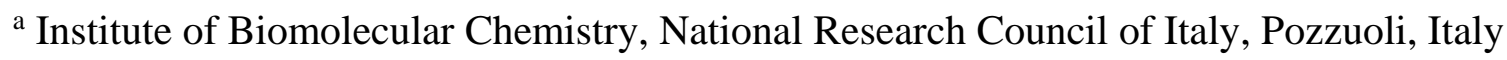

${ }^{\mathrm{b}}$ Department of Chemistry, University of Milan, Milan, Italy

${ }^{\mathrm{c}}$ Department of Food, Environmental and Nutritional Sciences, University of Milan, Milan, Italy

d Institute of Chemical Science and Technologies “G. Natta”, CNR-SCITEC, Milan, Italy

*Corresponding author: gtommonaro@icb.cnr.it; ORCID ID: http://orcid.org/0000-0002-9613-1843

Carlo F. Morelli: carlo.morelli@unimi.it

Marco Rabuffetti: marco.rabuffetti1@unimi.it

Barbara Nicolaus: bnicolaus@icb.cnr.it

Rocco De Prisco: roccodeprisco1@ virgilio.it

Carmine Iodice: ciodice@icb.cnr.it

Giovanna Speranza: giovanna.speranza@unimi.it

CONFLICTS OF INTEREST: The authors have no conflicts of interest to disclose

FUNDING: This research received no external funding

Data Availability Statement: Data available on request from the authors 


\begin{abstract}
Umami taste, known as appetizing sensation, is mainly imparted by monosodium glutamate (MSG, the first identified umami factor) in synergistic combination with some 5 ' ribonucleotides such as inosine 5'-monophosphate, IMP, guanosine 5'-monophosphate, GMP, and adenosine 5'monophoshate, AMP. The level of free glutamic acid in tomatoes is higher than in other vegetables or fruits and increases with ripening and industrial processing. In addition, due to the presence of bioactive metabolites, tomatoes and tomato-based products are among the most consumed healthy food items. The levels of the major umami compounds of tomato, i.e. glutamate and 5'ribonucleotides (GMP and AMP) were assessed in different parts (skin, outer flesh, inner pulp) of known tomato varieties from southern Italy: San Marzano Originale, San Marzano 245, Black Tomato, Corbarino Corbara, Corbarino Nocera and Superpomodoro (tomato hybrid). Such varieties were also investigated for their antioxidant properties through DMPD, DPPH and ABTS assays, with San Marzano Originale showing the highest antioxidant power both in lipophilic and methanolic fractions. The concentration of umami compounds in tomato differs with the part of the fruit analyzed and is greatly dependent on the variety, being Corbarino Nocera the cultivar richest in glutamate and Superpomodoro in ribonucleotides. As for nutritional aspect, results confirm the great nutraceutical feature of San Marzano tomato, the most known variety used in industrial processes.
\end{abstract}

\title{
PRACTICAL APPLICATION ABSTRACT
}

This study was planned to develop a method to quantify the major umami compounds that strongly influence the organoleptic properties of many different tomato varieties. It is known that sensory quality of fruits and vegetables are an important factor in consumer choice. The analytical methods described here enabled the evaluation of the glutamate and 5'-ribonucleotides content in six selected varieties of tomato from Campania region, and can be easily used to determine the sensory profile of commercial varieties, e.g. those perceived as not very tasteful by consumers. 
Keywords: Umami compounds, Ribonucleotides, Tomato, Antioxidant properties

\section{INTRODUCTION}

Umami taste in foods is elicited predominantly by the presence of monosodium L-glutamate and some purine 5'-ribonucleotides, in particular inosine, guanosine, and adenosine 5'-monophosphates $(\mathrm{IMP}, \mathrm{GMP}, \mathrm{AMP})^{1}$. Peculiar properties of umami compounds are their ability to enhance the flavor, mouthfulness and palatability of savory dishes and their mutual taste synergism. Therefore, these compounds are widely used, alone or in combination, as ingredients and taste enhancers in food industry ${ }^{2}$.

First discovered by Ikeda in 1908, umami was recognized as the fifth basic taste in the early 2000s, due to the identification of the specific receptors on taste buds ${ }^{3}$. The taste-mGluR4 and mGluR1tr receptors ${ }^{4}$ and the heterodimer T1R1 + T1R $3^{5}$, all belonging to the GPCRs superfamily (G proteincoupled receptors $)^{6}$, are recognized as glutamate receptors associated with the perception of umami taste. In humans, the T1R1 + T1R3 complex functions as a much more specific receptor, as it responds selectively to the monosodium glutamate (MSG), with a sensitivity that traces the human psychophysical thresholds for the umami taste ${ }^{7}$. Moreover, a possible interpretation of the characteristic synergistic effect of MSG and purine ribonucleotides on umami perception was proposed using a homology model of the Venus flytrap domain of the T1R1 subunit of the umami receptor ${ }^{8}$.

Among vegetables common to the traditional Mediterranean Diet, tomato has the highest content of L-glutamate. L-glutamate concentration increases dramatically during ripening up to be the most abundant free amino acid of ripe fruits of cultivated varieties. Such an increase has been shown to be correlated to the activity of some enzymes involved in glutamate metabolism such as $\gamma$-glutamyl transpeptidase $(\gamma$-GTase), glutamate dehydrogenase (GDH), $\alpha$-ketoglutarate-dependent $\gamma$ - 
aminobutyrate transaminase $(\mathrm{GABA}-\mathrm{T})^{9}$. In addition to glutamate, other umami compounds i.e. aspartic acid (showing only $7 \%$ of the taste activity of glutamate) and 5 '-ribonucleotides, in particular AMP and GMP, strongly contribute to the overall palatability of tomato fruits. AMP, which has an ability to enhance the taste intensity of MSG lower than that of GMP and IMP, is the major ribonucleotide in tomato ${ }^{10,11}$. On the other hand, reducing sugars and organic acids are mainly responsible of the sweet-sour taste of tomato fruits ${ }^{11}$.

Tomato and tomato-based products have a worldwide distribution and play an important role in human nutrition ${ }^{11-13}$. Several studies have shown the positive effect on health associated with tomato consumption to be due to the presence of a pool of antioxidants, with noticeable synergistic effects. The nutritional qualities of tomato depend on the cultivar, maturity stage, storage treatment and both agronomic and environmental conditions during cultivation ${ }^{14,15}$. Ripening and cooking produce an increase of bioactive metabolite levels as well as of glutamate content ${ }^{16-18}$.

In previous studies we investigated the nutraceutical properties of several tomato varieties, such as San Marzano and Corbarino, typical products of Campania, a region of southern Italy ${ }^{14,19}$, where soil composition and sun exposition represent the most appropriate conditions for tomato cultivation. Specifically, the relationship between genotypic factors and nutritional properties, in terms of antioxidant activity and bioactive metabolites content (polyphenols and carotenoids) was assessed.

In recent years, there has been a growth in consumer request for safe, high quality, full flavored foods as well as for locally produced fruits and vegetables ${ }^{20}$. In this respect, characterization of traditional varieties of tomato, in terms of nutritional features and taste-active compounds, is a response to these new consumption trends.

In this paper, some varieties of tomatoes of industrial interest, typical of Campania region, were investigated for their contents of umami tasting compounds in different parts of the fruit (skin, outer flesh, inner pulp) and for their nutritional parameters. Specifically, the glutamate and 5'-nucleotides concentration as well as the antioxidant activity were evaluated. 


\section{MATERIAL AND METHODS}

\section{Tomatoes samples}

San Marzano Originale (SMO), San Marzano 245 (SM245), Black Tomato (BT), Corbarino Corbara $(\mathrm{CoC})$, Corbarino Nocera $(\mathrm{CoN})$ e Superpomodoro (SP) were harvested in August 2019 at a maximum stage of ripening. The samples were kept at $-20^{\circ} \mathrm{C}$ in laboratory until analysis.

\section{Sample preparation}

For the taste components evaluation, each sample (150-400 g) was divided in three parts: peels, flesh and internal part (seeds plus fibers) and next lyophilized.

For the evaluation of antioxidant activity, samples were homogenized in a blender, centrifuged at 9,500 rpm for $20 \mathrm{~min}$, supernatants and pellets were collected separately and kept for analysis. To obtain the hydrophilic fraction, supernatants were utilized. Pellets were divided in two aliquots and extracted separately with methanol and diethyl ether (30 min under shaker for three times) with the aim to extract polyphenols and carotenoids, respectively $\left(100 \mathrm{~mL}\right.$ of $\mathrm{MeOH}$ and $\mathrm{Et}_{2} \mathrm{O}$ were used to extract $10 \mathrm{~g}$ of pellet). Then, the extracts were filtered and concentrated in a rotary evaporator in vacuum and dried under $\mathrm{N}_{2}$. The selected tomato varieties are listed in Table 1 as well as the weights of fresh products and their lyophilized parts.

\section{Chemicals}

Unless stated otherwise, all reagents, solvents and reference standards used were obtained from Sigma Aldrich Italia. Analytical-grade solvents were obtained from Carlo Erba (Rodano, Italy). Acetonitrile, methanol and dichloromethane (high performance liquid chromatography [HPLC] grade) from Merck (Darmstadt, Germany) were used. N,N-Dimethyl-p-phenylenediamine dihydrochloride (DMPD), 2,2'-azinobis(3-ethylbenzthiazoline-6-sulfonic acid) (ABTS) as the crystallized diammonium salt, and 2,2 diphenyl-1- picrylhydrazyl (DPPH) were from Fluka (Buchs, Switzerland).

\section{Apparatus and methods}




\section{HPLC and LC-MS/MS analysis conditions}

Glutamic acid content was measured with a Rigol L-3000 HPLC system equipped with a double diode UV detector using a RP-18 Gemini column (250 mm x $4.6 \mathrm{~mm}$ i.d., $5 \mu \mathrm{m}$, Phenomenex). HPLC instrument was interfaced with a PC running Clarity (Laserchrom) software. The following linear gradient (Method A) of $0.1 \%$ aqueous TFA (solvent A) and acetonitrile/solvent A $80: 20$ (solvent B) was used: 0-10 min, isocratic elution solvent A : solvent B $80: 20 ; 10-30 \mathrm{~min}$, gradient to solvent A : solvent B 40 : 60; 30-40 min, isocratic elution solvent A : solvent B 40 : 60; 40-60 min, gradient to solvent A : solvent B 80 : 20. Flow rate was $0.75 \mathrm{~mL} / \mathrm{min}$; detection was at $356 \mathrm{~nm}$ and injection volume was $20 \mu \mathrm{L}$.

Ribonucleotides content was measured using a LC-4000 (Jasco) HPLC instrument connected to an UV/Vis detector model UV 4070 (JASCO) and interfaced to a PC running the ChromNav software package (Chromatography Data System, Jasco). UHPLC analyses of ribonucleotides were carried out on a UltiMate 3000 instrument (Thermo Fisher Scientific) connected to a ESI LCQ Fleet mass spectrometer with ion trap detector (Thermo Fisher Scientific).

A LiChrospher $100 \mathrm{RP}-18(5 \mu \mathrm{m})$ LiChroCART column $(250 \mathrm{~mm}$ x $4.6 \mathrm{~mm}$ i.d.) was used for both HPLC and UHPLC analyses. Elution (Method B) was in isocratic mode using $0.1 \%$ TFA/acetonitrile in $99.5: 0.5$ ratio at $0.75 \mathrm{~mL} / \mathrm{min}$. Detection was at $\lambda 254 \mathrm{~nm}$. Injection volume was $20 \mu \mathrm{L}$.

\section{UV-vis measurements}

Absorbances were recorded at controlled room temperature $\left(25^{\circ} \mathrm{C}\right)$ with a Varian (Palo Alto, CA, USA) DMS 90 UV-VIS spectrophotometer.

\section{${ }^{1} \mathrm{H}$ NMR analysis}

${ }^{1} \mathrm{H}$ NMR spectra were acquired at $400.13 \mathrm{MHz}$ using a Bruker Avance 400 spectrometer (Bruker, Karlsruhe, Germany) interfaced with a workstation running Windows Operating System (Microsoft, 
Redmond, WA, USA) equipped with TopSpin Software package. Chemical shifts are given in ppm $(\delta)$ and are referenced to the signals of the solvent $\left(\mathrm{D}_{2} \mathrm{O}, \delta_{\mathrm{H}}=4.71\right)$.

\section{Analysis of glutamic acid}

To determine the glutamate content,lyophilized tomato sample $(100 \mathrm{mg})$ was put into a fritted tube and extracted with $0.1 \mathrm{M}$ sodium borate buffer, $\mathrm{pH} 8.5(4 \mathrm{~mL})$ at $21^{\circ} \mathrm{C}$ for $30 \mathrm{~min}$ with shaking. After removal of the solution by filtration using a FlashVac Biotage apparatus, the solid material in the tube was extracted three more times following the same procedure.

Sample solution for analysis was obtained by combining equal amounts of solutions deriving from the four extractions.

In a pyrex tube equipped with a perforated screw cap and a septum, sample solution $(250 \mu \mathrm{L})$ was charged, followed by $5 \mathrm{mM} S$-methylcysteine solution as the internal standard $(100 \mu \mathrm{L})$ and $0.1 \mathrm{M}$ sodium borate buffer, $\mathrm{pH} 8.5(250 \mu \mathrm{L})$. 1-fluoro-2,4-dinitrobenzene (Sanger's reagent) solution in acetone $(5 \mathrm{mM}, 500 \mu \mathrm{L})$ was then added; the tube was tightly sealed and heated at $70{ }^{\circ} \mathrm{C}$ in a water bath. After 45 min a needle was inserted through the septum of the tube's cap and heating was continued for additional $10 \mathrm{~min}$ in order to evaporate most of the acetone. The derivatized solution was diluted in equal proportions with $0.1 \%$ TFA aqueous solution and analyzed by HPLC using method A. Extraction procedures and subsequent analyses were carried out in triplicate. Identification of the glutamic acid peak was achieved by comparison of the retention value and coelution with an authentic samples of 2,4-dinitrophenylderivative of glutamic acid, which was also used to prepare the calibration curves.

\section{Analysis of 5'-ribonucleotides}

Lyophilized tomato sample $(500 \mathrm{mg})$ was put in a fritted tube and extracted with $0.05 \mathrm{M} \mathrm{HCl}(10$ $\mathrm{mL}$ ) for $30 \mathrm{~min}$ at $21^{\circ} \mathrm{C}$. The solution was removed by filtration by means of a FlashVac Biotage apparatus and the solid material in the tube was subjected to two more extractions in the same conditions. Equal amounts of solutions deriving from the three extractions were combined, filtered 
through a $0.45 \mu \mathrm{m}$ Millipore filter and analyzed by HPLC using method B.

All samples were analyzed in triplicate. Mixtures of GMP and AMP at different concentrations were used for calibration.

\section{Antioxidant activity assays}

The antioxidant activity was evaluated by using the DMPD, DPPH and ABTS methods ${ }^{21-23}$ which are based on the capacity of different components to inhibit the DMPD and ABTS radical cations $\left(\mathrm{DMPD}^{\circ+}\right.$ and $\mathrm{ABTS}^{\circ+}$, respectively) and $\mathrm{DPPH}^{*}$ radical. The antioxidant capacity was expressed both as radical percentage inhibition, calculated by the following formula:

$$
\operatorname{Abs}(\%)=\left(1-\mathrm{Ab}_{s f} / \mathrm{Abs} 0\right) \times 100
$$

where $\mathrm{Abs} 0$ and $\mathrm{Ab}_{s f}$ were the absorbance before and after the addition of sample, respectively, and as $\mu \mathrm{g}$ equivalent of Trolox. All assays were carried out in triplicate and values were reported $\pm \mathrm{SD}$.

\section{DMPD assay}

For the hydrophilic antioxidant activity, the reaction mixture contained $1 \mathrm{mM}$ DMPD, $0.1 \mathrm{mM}$ ferric chloride in acetate buffer $0.1 \mathrm{M}(\mathrm{pH} 5.25)$ in a total volume of $1 \mathrm{~mL}$. The reaction was monitored at $505 \mathrm{~nm}$ until absorbance became stable. Then, $2.5 \mu \mathrm{L}$ of aqueous phase was added to the reaction medium and the decrease in absorbance, which is proportional to the $\mathrm{DMPD}^{\circ+}$ quenched, was determined after 20 minutes.

\section{DPPH assay}

Antioxidant activity of methanolic fraction of all samples was determined by DPPH method. Briefly, $50 \mu \mathrm{L}$ of extract solution $\left(10 \mathrm{mg} \mathrm{mL}^{-1}\right)$ was added to $0.7 \mathrm{~mL}$ of DPPH in methanol $(0.1 \mathrm{mM}$ final concentration) and adjusted to a final volume of $2 \mathrm{~mL}$. The absorbance was determined after 30 minutes at $517 \mathrm{~nm}$ at room temperature. 


\section{ABTS assay}

For the lipophilic antioxidant activity, the reaction mixture contained $56 \mu \mathrm{M}$ ABTS and $24.5 \mu \mathrm{M}$ $\mathrm{K}_{2} \mathrm{~S}_{2} \mathrm{O}_{8}$ (CAS: 7727-21-1) in ethanol (dilution 1:100) in a total volume of $1 \mathrm{~mL} .5 \mu \mathrm{L}$ of the lipophilic extract $\left(10 \mathrm{mg} \mathrm{mL}^{-1}\right)$ was added to the reaction medium and the decrease in absorbance at $734 \mathrm{~nm}$ was determined after 5 minutes. The total time needed to carry out each assay was approximately 6 minutes. According to the ABTS method, the lipophilic antioxidant activity was carried out in triplicate on crude diethyl ether extract of each sample, dissolved in dichloromethane analytical grade.

\section{Statistical analysis}

Analysis of variance (ANOVA) and Tukey post-hoc test at 95\% confidence level were used for determining significant differences in the concentration of glutamic acid, AMP and GMP within the three parts of the fruits and among the different varieties considered. Calculations were carried out using PSPP (www.gnu.org/software/pspp).

\section{RESULTS AND DISCUSSION}

The weights of fresh tomato samples of the six varieties investigated, i.e. San Marzano Originale (SMO), San Marzano 245 (SM245), Black Tomato (BT), Corbarino Corbara (CoC), Corbarino Nocera (CoN) e Superpomodoro (SP), as well as the number of fruits used and the amount of the resulting lyophilized parts (skin, outer flesh and inner pulp) are reported in Table 1.

Table 1. Selected tomato varieties and the yield of lyophilized material.

\begin{tabular}{c|c|c|c|c}
\hline \hline Samples & $\begin{array}{c}\text { Fresh } \\
\text { product } \\
(\mathbf{g})\end{array}$ & $\begin{array}{c}\text { Lyophilized } \\
\text { skin } \\
(\mathbf{g})\end{array}$ & $\begin{array}{c}\text { Lyophilized } \\
\text { outer flesh } \\
(\mathbf{g})\end{array}$ & $\begin{array}{c}\text { Lyophilized } \\
\text { inner pulp } \\
(\mathbf{g})\end{array}$ \\
\hline $\begin{array}{c}\text { Superpomodoro } \\
\text { (N.3 fruits) }\end{array}$ & 327.50 & 2.29 & 8.93 & 6.76 \\
\hline
\end{tabular}




\begin{tabular}{c|c|c|c|c}
\hline $\begin{array}{c}\text { S. Marzano } \\
\text { originale } \\
\text { (N.4 fruits) }\end{array}$ & 212.34 & 2.31 & 6.32 & 4.00 \\
\hline $\begin{array}{c}\text { Black tomato } \\
\text { (N.1 fruit) }\end{array}$ & 429.00 & 1.41 & 20.84 & 11.35 \\
\hline $\begin{array}{c}\text { Corbarino } \\
\text { Nocera } \\
\text { (N.21 fruits) }\end{array}$ & 175.27 & 3.56 & 4.45 & 6.79 \\
\hline $\begin{array}{c}\text { S. Marzano 245 } \\
\text { (N.4 fruits) }\end{array}$ & 256.00 & 3.35 & 6.99 & 5.50 \\
\hline $\begin{array}{c}\text { Corbarino } \\
\text { Corbara }\end{array}$ & 170.33 & 3.10 & 4.86 & 5.16 \\
\hline \begin{tabular}{c} 
(N.21 fruits) \\
\hline
\end{tabular}
\end{tabular}

\section{Analysis of umami compounds}

As umami plays a major role in the acceptability of many foods by the consumers, evaluation of the levels of umami tasting compounds is an important issue in assessing the quality characteristics of tomato cultivars

For glutamate analysis a HPLC method based on a pre-column derivatization with Sanger's reagent in the presence of an internal standard was used (see Experimental for details).

To quantify the glutamate content a calibration curve was prepared in such a way to comprise roughly as central point the concentration of glutamic acid corresponding to the mean content of this amino acid in tomatoes ${ }^{10}$. Data reported in Table 2 and Fig. 1 are average values of triplicate analyses of the three extracts of each sample of skin, outer flesh and inner pulp of the different varieties of tomato.

Analytical data were subjected to statistical analysis in order to determine relevant differences in the content of umami compounds in the same part of the fruit among the six varieties. ANOVA followed by Tukey post-hoc test at $95 \%$ confidence interval was carried out considering each part of the fruit independently. Statistically significant differences are highlighted in Fig. 1. 
Table 2. Taste active compound contents in tomatoes

\begin{tabular}{|c|c|c|c|c|c|c|c|}
\hline & & $\begin{array}{c}\text { Corbarino } \\
\text { Corbara }\end{array}$ & $\begin{array}{c}\text { Corbarino } \\
\text { Nocera }\end{array}$ & $\begin{array}{c}\text { S. Marzano } \\
\text { Originale }\end{array}$ & $\begin{array}{c}\text { S. Marzano } \\
245\end{array}$ & $\begin{array}{c}\text { Black } \\
\text { tomato }\end{array}$ & Superpomodoro \\
\hline \multirow{3}{*}{$\begin{array}{c}\text { Glu } \\
\left(\mathrm{g} \mathrm{kg}^{-1}\right)\end{array}$} & Skin & $41.40 \pm 1.25$ & $31.22 \pm 2.37$ & $26.54 \pm 2.01$ & $24.57 \pm 1.58$ & $20.44 \pm 0.68$ & $25.34 \pm 1.12$ \\
\hline & Outer flesh & $52.99 \pm 2.10$ & $59.21 \pm 2.92$ & $37.93 \pm 2.87$ & $51.13 \pm 2.65$ & $47.67 \pm 2.08$ & $37.21 \pm 2.60$ \\
\hline & Inner pulp & $49.82 \pm 1.73$ & $57.08 \pm 0.80$ & $32.67 \pm 2.52$ & $44.70 \pm 1.18$ & $42.90 \pm 2.09$ & $43.13 \pm 2.25$ \\
\hline \multirow{3}{*}{$\begin{array}{l}5^{\prime}-A M P \\
\left(\mathrm{mg} \mathrm{kg}^{-1}\right)\end{array}$} & Skin & $160 \pm 22$ & $33 \pm 1$ & $234 \pm 79$ & $1024 \pm 36$ & $92 \pm 9$ & $87 \pm 24$ \\
\hline & Outer flesh & $344 \pm 34$ & $60 \pm 23$ & $917 \pm 15$ & $1907 \pm 24$ & $470 \pm 23$ & $975 \pm 138$ \\
\hline & Inner pulp & $1024 \pm 12$ & $257 \pm 32$ & $1578 \pm 132$ & $3385 \pm 277$ & $611 \pm 19$ & $4851 \pm 14$ \\
\hline \multirow{3}{*}{$\begin{array}{l}5^{\prime}-\mathrm{GMP} \\
\left(\mathrm{mg} \mathrm{kg}^{-1}\right)\end{array}$} & Skin & $108 \pm 21$ & 142 & $168 \pm 39$ & 139 & $97 \pm 13$ & $85 \pm 5$ \\
\hline & Outer flesh & $83 \pm 9$ & 112 & $158 \pm 24$ & $87 \pm 8$ & $121 \pm 5$ & $170 \pm 10$ \\
\hline & Inner pulp & $78 \pm 9$ & $248 \pm 1$ & $159 \pm 3$ & $149 \pm 24$ & $178 \pm 6$ & $517 \pm 2$ \\
\hline
\end{tabular}



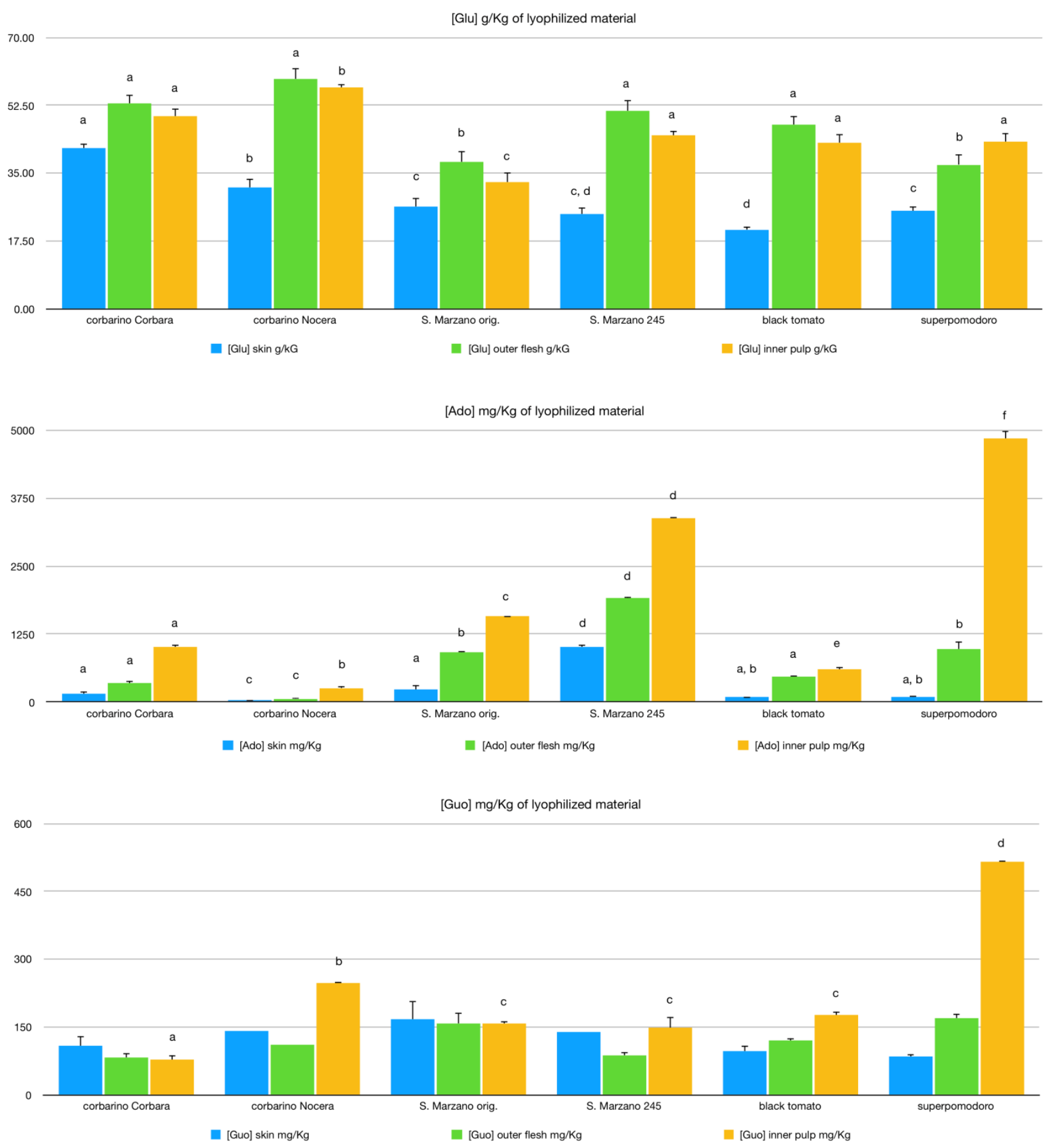

Figure 1. Glutamic acid, AMP and GMP content in tomatoes. Different letters mean statistically relevant differences $(\mathrm{p}<0.05)$ in Tukey post-hoc test among the same part of the fruit in the six varieties.

For all the varieties examined, the concentration of glutamic acid in the skin is lower than in the other parts of the fruit ranging from $20.44 \mathrm{~g} \mathrm{~kg}^{-1}$ of BT to $41.40 \mathrm{~g} \mathrm{~kg}^{-1}$ of CoC. In addition, the outer flesh contains always the highest level of glutamate except in the case of SP, in which the highest concentration of glutamate $\left(43.13 \mathrm{~g} \mathrm{~kg}^{-1}\right)$ was found in the inner gelatinous jelly. 
With regard to the outer flesh, CoN showed the highest level of glutamate $\left(59.21 \mathrm{~g} \mathrm{~kg}^{-1}\right)$, without statistically significant differences with respect to CoC (52.99 $\left.\mathrm{g} \mathrm{kg}^{-1}\right)$, SM245 (51.13 $\left.\mathrm{g} \mathrm{kg}^{-1}\right)$ and BT( $47.67 \mathrm{~g} \mathrm{~kg}^{-1}$ ). SP and SMO were found to have a lower level of glutamate in this part of the fruit (37.21 $\mathrm{g} \mathrm{kg}^{-1}$ and $37.93 \mathrm{~g} \mathrm{~kg}^{-1}$, respectively), without statistically relevant differences between them. As stated previously, SP exhibited a higher content of glutamate in the inner pulp than in outer flesh, but this value (43.13 $\mathrm{g} \mathrm{kg}^{-1}$ ) does not represent the highest level of glutamate found in this part of the fruit among the tested varieties, as it ranges from $57.08 \mathrm{~g} \mathrm{~kg}^{-1}$ of $\mathrm{CoN}$ to $32.67 \mathrm{~g} \mathrm{~kg}^{-1}$ of SMO. CoC, SM245 and BT showed a glutamate content in the inner pulp similar to that of SP, and no statistically significant differences were observed.

5'-Ribonucleotides were extracted from the lyophilized tomato samples (skin, outer flesh and inner gelatinous juice) with $0.05 \mathrm{M} \mathrm{HCl}$ following the procedure reported by Oruna-Concha et al. ${ }^{10}$ with some modifications. Extraction was monitored by ${ }^{1} \mathrm{H}-\mathrm{NMR}$ spectroscopy, a technique that is becoming increasingly used in food science in recent years for the analysis of complex matrices ${ }^{24}$.

${ }^{1} \mathrm{H}$ NMR spectra (400 MHz) of the extracts, recorded in $\mathrm{D}_{2} \mathrm{O}$, are in agreement with those reported in the literature ${ }^{25,26}$ and showed signals attributable to glutamate, glutamine and citric acid (in the aminoand organic acid region) and glucose and fructose (in the sugar region). As for the aromatic region, beside signals of aromatic amino acids, flavonoids, and other aromatic compounds such as trigonelline, characteristic resonances of 5'-nucleotides were present. In particular those of 5'-AMP (signals at 8.51, 8.12, and 6.07 ppm for H-8, H-2 and H-1', respectively) could be easily recognized. Among the several protocol reported in the literature for the analysis of nucleotides in biological systems $^{27,28}$, we chose a RPLC method and the elution system reported by Xue et al. ${ }^{29}$ with some modifications.

The use of an UHPLC/ESIMS apparatus and a mixture of five 5'-ribonucleotides as reference standards allowed the assessment of the order of elution of 5'-UMP, 5'-CMP, 5'-IMP, 5'-AMP and 
5'-GMP identified by the corresponding molecular ion peaks at $\mathrm{m} / \mathrm{z} 323.23,322.24,347.25,346.27$, and 362.25, respectively, in the negative-ion mode spectra. Except for 5'-IMP, the selected nucleotides were detected in all tomato samples investigated, although in variable amount, with 5'AMP always present at the highest concentration.

Quantification of umami 5'-ribonucleotides (AMP and GMP) was conducted by using an HPLC apparatus and external calibration curves. Under the selected chromatographic conditions, a poor resolution of CMP and UMP was achieved, while peaks of AMP and GMP were well separated each others. Our results indicate that AMP is more abundant than GMP in the analyzed samples up to 22 times (Table 2). AMP concentrates in the inner gelatinous jelly, showing here also its major variability, as it ranges from $257 \mathrm{mg} \mathrm{kg}^{-1}$ in CoN to $4851 \mathrm{mg} \mathrm{kg}^{-1}$ in SP. Its content in this part of the fruit is statistically different for each variety of tomato. With respect to other varieties, SM245 showed the highest concentration of AMP in outer flesh $\left(1907 \mathrm{mg} \mathrm{kg}^{-1}\right)$. In this part of the fruit, similar levels of AMP were found both in SP and SMO (975 mg kg-1 and $917 \mathrm{mg} \mathrm{kg}^{-1}$, respectively) and in CoC and BT (344 mg kg-1 and $470 \mathrm{mg} \mathrm{kg}^{-1}$, respectively). CoN showed the lowest levels of AMP in all the part of the fruit (33.60 and $267 \mathrm{mg} \mathrm{kg}^{-1}$ for skin, outer flesh and inner pulp, respectively).

The other ribonucleotide evaluated, GMP, has a different distribution in the three parts of tomato fruits. Indeed, it does not concentrate in inner gelatinous jelly in all the tested varieties, and its content showed minor variability in this part of the fruit: SMO, SM245 and BT showed statistically similar concentrations (159, 149 and $178 \mathrm{mg} \mathrm{kg}^{-1}$, respectively). Moreover, in SMO and in CoC there is not statistically difference in GMP concentrations among the three parts of the fruit (in the range 78-108 $\mathrm{mg} \mathrm{kg}^{-1}$ and 158-168 $\mathrm{mg} \mathrm{kg}^{-1}$, respectively), with CoC containing the lowest level of GMP, compared to the other varieties. It can be noticed that the inner gelatinous jelly of SP exhibited the highest level of GMP (517 mg kg$\left.{ }^{-1}\right)$ together with the highest level of AMP (4851 $\mathrm{mg} \mathrm{kg}^{-1}$ ), while the GMP content in the outer flesh of SP is not different from that of SMO (170 and $158 \mathrm{mg} \mathrm{kg}^{-1}$, respectively). 


\section{Antioxidant activity}

Many epidemiological studies suggest that tomato consumption reduces the risk of chronic diseases, such as cardiovascular disease and cancer, by increasing the protection of the organism against free radicals (from oxidative stress). This protective action is typically attributed to the synergistic effect different antioxidants present in tomatoes ${ }^{30-32}$.

Data of the antioxidant properties of the aqueous, methanolic and lipophilic fractions obtained from the six varieties of tomatoes under investigation, by extraction of the fresh material with water, methanol and ethyl ether, respectively, are reported in Table 3. For all samples analyzed, a high percentage of ABTS cation radical inhibition (ranging from 58\% to $100 \%$ ) was observed for the lipophilic fraction containing mainly carotenoids (lycopene and $\beta$-carotene). The SM245 extract displayed the highest value (100\% inhibition) followed by SMO (89\% of inhibition).

It is worth noting that SM245, mainly used for the production of tomato derivatives such as peeled tomatos, possesses the highest content of 5'-AMP, the most abundant umami-tasting ribonucleotide of tomato, both in the skin and in the outer flesh. SM245 differs from SMO for its greater resistance to parasitic disease and higher plant productivity. These features, obtained by careful selection by agronomists and farmers over the centuries, make SM245 a variety more suitable than SMO for industrial processes.

The antioxidant activity of the aqueous extracts, evaluated by means of DMPD method, ranged from 25 to $56 \%$ with those of SMO, SM245 and CoC showing very close values (ca. 37-38\%). By contrast, a higher variability in the antioxidant capacity was observed for the methanol extracts (DPPH assay) as percentage inhibition of DPPH radical from $10.3 \%$ for SP to $49.8 \%$ and $49.4 \%$ for SMO and CoC, respectively, were observed. In addition, the remaining varieties showed intermediate values and very similar to each other (from $23.5 \%$ of $\mathrm{CoN}$ to $27.2 \%$ of SM245). This result may be attributed to the difference in the content of polyphenols (flavonoids, hydroxycinnamic acids, etc.) ${ }^{11}$ among the tomato varieties investigated. 
Table 3. Antioxidant activity of lipophilic, aqueous and methanolic tomato extracts evaluated by means of ABTS, DMPD and DPPH assays, respectively.

\begin{tabular}{|c|c|c|c|c|c|c|}
\hline \multirow{2}{*}{ Tomato cultivars } & \multicolumn{2}{|c|}{$\begin{array}{c}\text { ABTS }^{+} \\
\left(5 \mu \mathrm{l} \text { of a solution } 10 \mathrm{mg} \mathrm{ml}^{-1}\right)\end{array}$} & \multicolumn{2}{|c|}{$\begin{array}{c}\text { DMPD }^{\dagger} \\
(2,5 \mu \mathrm{l} \text { of aqueous extract })\end{array}$} & \multicolumn{2}{|c|}{$\begin{array}{c}\text { DPPH }^{\dagger} \\
\left(50 \mu \mathrm{l} \text { of a solution } 10 \mathrm{mg} \mathrm{ml}^{-1}\right)\end{array}$} \\
\hline & $\begin{array}{c}\% \\
\text { inihibition }\end{array}$ & $\begin{array}{l}\mu \mathrm{g} \text { eq. } \\
\text { Trolox }\end{array}$ & $\begin{array}{c}\% \\
\text { inihibition }\end{array}$ & $\begin{array}{l}\mu \text { g eq. } \\
\text { Trolox }\end{array}$ & $\begin{array}{c}\% \\
\text { inihibition }\end{array}$ & $\begin{array}{l}\mu \mathrm{g} \text { eq. } \\
\text { Trolox }\end{array}$ \\
\hline $\begin{array}{c}\text { San Marzano } \\
\text { Originale (SMO) }\end{array}$ & $89.21 \pm 1.37$ & $66.75 \pm 0.78$ & $37.42 \pm 0.57$ & $59.08 \pm 0.65$ & $49.83 \pm 0.85$ & $10.13 \pm 0.35$ \\
\hline $\begin{array}{c}\text { San Marzano } \\
245 \text { (SM245) }\end{array}$ & $100.16 \pm 1.61$ & $75.00 \pm 1.04$ & $38.61 \pm 0.61$ & $60.97 \pm 0.83$ & $27.21 \pm 0.54$ & $5.53 \pm 0.27$ \\
\hline $\begin{array}{c}\text { Corbarino di } \\
\text { Corbara }(\mathrm{CoC})\end{array}$ & $83.36 \pm 0.87$ & $62.25 \pm 1.10$ & $38.70 \pm 0.85$ & $61.13 \pm 0.79$ & $49.40 \pm 0.78$ & $10.05 \pm 0.61$ \\
\hline $\begin{array}{l}\text { Corbarino di } \\
\text { Nocera }(\text { CoN })\end{array}$ & $85.28 \pm 0.69$ & $63.75 \pm 0.73$ & $47.70 \pm 1.10$ & $75.35 \pm 0.70$ & $23.54 \pm 1.23$ & $4.78 \pm 0.48$ \\
\hline $\begin{array}{c}\text { Superpomodoro } \\
\text { (SP) }\end{array}$ & $79.18 \pm 1.54$ & $59.25 \pm 0.81$ & $56.02 \pm 1.03$ & $88,46 \pm 0.91$ & $10.32 \pm 0.82$ & $2.09 \pm 0.58$ \\
\hline $\begin{array}{l}\text { Black Tomato } \\
\text { (BT) }\end{array}$ & $58.25 \pm 0.77$ & $43.50 \pm 0.79$ & $25.04 \pm 0.63$ & $39.49 \pm 0.88$ & $25.03 \pm 0.69$ & $5.08 \pm 0.38$ \\
\hline
\end{tabular}

${ }^{\dagger}$ Antioxidant activity is reported both as percentage of inhibition of ABTS and DMPD radical cations and DPPH radical and as $\mu \mathrm{g}$ eq. Trolox. Values are reported $\pm \mathrm{SD}$

It is known that sensory quality of fruits and vegetables are an important factor in consumer choice ${ }^{33}$. This is particularly true in that case of tomato as breeding efforts over the last 100 years were focused on improving disease resistance, yield and agronomic and technological properties but neglected other important aspects such as flavor and nutritional features ${ }^{34,35}$. On the other hand, tomato flavor is a trait that is difficult to determine quantitatively. This study was planned to develop a method to quantify the major umami compounds that strongly influence the organoleptic properties of many foods including tomato. The analytical methods described here enabled the evaluation of the glutamate and 5'-ribonucleotides content in six selected varieties of tomato from Campania region, 
and can be easily used to determine the sensory profile of commercial varieties, e.g. those perceived as not very tasteful by consumers.

\section{CONCLUSIONS}

In conclusion, as umami is an important component of tomato flavor and antioxidant activity an index of its nutritional quality, this study can have a significant impact for the use of traditional varieties and new hybrids in agri-food industry. The finding that the taste-active compounds are differently distributed in the different parts of the fruit (skin, outer flesh and inner pulp) may be a useful parameter in the selection of the most suitable variety for a specific industrial production.

\section{References}

1. Behrens M, Meyerhof W, Hellfritsch C and Hofmann T, Sweet and umami taste: natural products, their chemosensory targets, and beyond. Angew Chem Int Ed 50:2220-2242 (2011).

2. Cairoli P, Pieraccini S, Sironi M, Morelli CF, Speranza G and Manitto P, Studies on umami Taste. Synthesis of new guanosine 5'-phosphate derivatives and their synergistic effect with monosodium glutamate. J Agric Food Chem 56:1043-1050 (2008).

3. Kurihara K, Umami the fifth basic taste: history of studies on receptor mechanisms and role as a food flavor. BioMed Res Int, 2015: 1-11, Article ID 189402 (2015).

4. Pal Choudhuri S, Delay RJ and Delay ER, Metabotropic glutamate receptors are involved in the detection of IMP and L-amino acids by mouse taste sensory cells. Neuroscience (Amsterdam, Neth.) 316:94-108 (2016).

5. Zhao GQ, Zhang Y, Hoon MA, Chandrashekar J, Erlenbach I, Ryba NJP and Zuker CS, The receptors for mammalian sweet and umami taste. Cell (Cambridge, MA, U. S.) 115:255-266 (2003).

6. Ozeck M, Brust P, Xu H and Servant G, Receptors for bitter, sweet and umami taste couple to inhibitory G protein signaling pathways. Eur J Pharmacol 489:139-149 (2004). 
7. Nelson G, Chandrashekar J, Hoon MA, Feng L, Zhao G, Ryba NJ, Zuker CS, An aminoacid taste receptor. Nature 416:199-202 (2002).

8. Zhang F, Klebansky B, Fine RM, Xu H, Pronin A, Liu H, Tachdjian C and Li X, Molecular mechanism for the umami taste synergism. Proc. Natl. Acad. Sci. U. S. A. 105:20930-20934 (2008).

9. Sorrequieta A, Ferraro G, Boggio SB and Valle EM, Free amino acid production during tomato fruit ripening: A focus on L-glutamate. Amino Acids 38:1523-1532 (2010).

10. Oruna-Concha MJ, Methven L, Blumenthal H, Young C and Mottram DS, Differences in glutamic acid and 5'-ribonucleotide contents between flesh and pulp of tomatoes and the relationship with umami taste. J Agric Food Chem 55:5776-5780 (2007).

11. Paolo D, Bianchi G, Lo Scalzo R, Morelli CF, Rabuffetti M and Speranza G, The chemistry behind tomato quality. Nat Prod Commun 13:1225-1232 (2018).

12. Tommonaro G, De Prisco R, Abbamondi GR, Marzocco S, Saturnino C, Poli A and Nicolaus B, Evaluation of antioxidant properties, total phenolic content, and biological activities of new tomato hybrids of industrial interest. J Med Food 15:483-489 (2012).

13. Tommonaro G, De Prisco R, Pergamo R, Iodice C, Abbamondi GR, Spagnuolo A and Nicolaus B, Effects of industrial processes on antioxidant power and polyphenols profile in cherry tomato cultivar. J Med Food 18 (10):1173-1178 (2015).

14. Barone D, Cito L, Tommonaro G, Abate AA, Penon D, De Prisco R, Penon A, Forte IM, Benedetti E, Cimini A, Indovina P, Nicolaus B, Pentimalli F and Giordano A, Antitumoral potential, antioxidant activity and carotenoid content of two southern italy tomato cultivars extracts: San Marzano and Corbarino. J Cell Physiol 233 (2): 1266-1277 (2018).

15. Chaudhary P, Sharma A, Singh B and Nagpal AK, Bioactivities of phytochemicals present in tomato. J Food Sci Technol 55: 2833-2849 (2018).

16. Ninomiya K, Umami: natural occurence. Food Rev Int 14:177-211 (1998). 
17. Inaba $\mathrm{A}$, Yamamoto $\mathrm{T}$, Ito $\mathrm{T}$ and Nakamura $\mathrm{R}$, Changes in the concentration of free amino acids and soluble nucleotides in attached and detached tomato fruits during ripening. $J J p n$ Soc Hortic Sci 49:435-441 (1980).

18. Petro-Turza M, Flavour of tomato and tomato products. Food Rev Int 2:309-351 (1986).

19. Strazzullo G, De Giulio A, Tommonaro G, La Pastina C, Saturnino C, Poli A, Nicolaus B, De Prisco R, Anti-oxidative activity and lycopene and $\beta$-carotene contents in different cultivars of tomato (Lycopersicon esculentum). Int J Food Properties 10 (2): 321-329 (2007).

20. Joosten F, Dijkxhoorn Y, Sertse Y, and Ruben R, How does the Fruit and Vegetable Sector contribute to Food and Nutrition Security? Wageningen, LEI Wageningen UR (University \& Research centre) 2015.

21. Blois MS, Antioxidant determinations by the use of a stable free radical. Nature 26:1199$1200(1958)$.

22. Miller NJ, Sampson J, Candeias LP, Bramley PM and Rice-Evans CA, Antioxidant activities of carotenes and xanthophylls. FEBS Lett 384:240-242 (1996).

23. Fogliano V, Verde V, Randazzo G and Ritieni A, Method for measuring antioxidant activity and its application to monitoring the antioxidant capacity of wines. J Agric Food Chem 47:1035-1040 (1999).

24. Corsaro G, Mallamace D, Vasi S, Ferrantelli V, Dugo G, Cicero N, ${ }^{1}$ HR-MAS NMR spectroscopy and the metabolite determination of typical foods in Mediterranean diet. J Anal Meth Chem ID 175696 (2015)

25. Le Gall GL, Colquhoun IJ, Davis AL, Collins GJ and Verhoeyen ME, Metabolite profiling of tomato (Lycopersicon esculentum) using ${ }^{1} \mathrm{H}$ NMR spectroscopy as a tool to detect potential unintended effects following a genetic modification. J Agric Food Chem 51:2447-2456 (2003). 
26. Consonni R, Cagliani LR, Stocchero M and Porretta S, Triple concentrated tomato paste: discrimination between Italian and Chinese products. J Agric Food Chem 57:4506-4513 (2009).

27. Hayama $\mathrm{T}$ and Ohyama $\mathrm{K}$, Recent development and trends in sample extraction and preparation for mass spectrometric analysis of nucleotides, nucleosides, and proteins. $J$ Pharm Biomed Anal 161:51-60 (2018).

28. Mateos-Vivas M, Fanali S, Rodrıguez-Gonzalo E, Carabias-Martınez R and Aturki Z, Rapid determination of nucleotides in infant formula by means of nano-liquid chromatography. $J$ Sep Sci 37:1873-1880 (2016).

29. Xue X, Wang F, Zhou J, Chen F, Li Y and Zhao J, Online cleanup of accelerated solvent extractions for determination of adenosine 5'-triphosphate (ATP), adenosine 5' -diphosphate (ADP), and adenosine 5'-monophosphate (AMP) in royal jelly using High-Performance Liquid Chromatography. J Agric Food Chem 57:4500-4505 (2009).

30. Ramos-Bueno RP, Romero-Gonzalez R, Gonzalez-Fernandez MJ and Guil-Guerrero JL, Phytochemical composition and in vitro antitumor activities of selected tomato varieties. $J$ Sci Food Agric 97:488-496 (2017).

31. Kolberg M, Pedersen S, Bastani NE, Carlsen H, Blomhoff R and Paur I, Tomato paste alters NF-kappaB and cancer-related mRNA expression in prostate cancer cells, xenografts, and xenograft microenvironment. Nutr Cancer 67:305-315 (2015).

32. Giovannucci E, Tomatoes, tomato-based products, lycopene, and cancer: Review of the epidemiologic literature. J Natl Cancer Inst 91:317-331 (1999).

33. Causse M, Friguet C, Coiret C, Lépicier M, Navez B, Lee M, Holthuysen N, Sinesio F, Moneta E, Grandillo S, Consumer preferences for fresh tomato at the European scale: a common segmentation on taste and firmness. J Food Sci 75:S531-S541 (2010).

34. Salles C, Tomato and flavor. In Tomatoes and Tomato Products. Preedy V, Watson RR (Eds). Science Publisher, Enfield, NH, USA, 85-110 (2008). 
35. Klee HJ, Tieman DM, Genetic challenges of flavor improvement in tomato. Trends Genet 29:257-262 (2013). 